\title{
De la metafísica a la anarquía. El pensamiento político de Reiner Schürmann
}

\section{From metaphysics to anarchy. The political thought of Reiner Schürmann}

\author{
Valerio D'ANGELO \\ (Universidad Autónoma de Madrid)
}

Recibido: 01/03/2016

Aceptado: 05/04/2016

\section{Resumen}

El artículo pretende abordar el modo en el que la obra de Reiner Schürmann, a través de un original interpretación del pensamiento de Martin Heidegger, consigue desarrollar un tipo de filosofía política anárquica. Se intentará analizar, en la dispersa obra del filósofo holandés, la idea de anarquía como condición existencial, prestando especial atención al nexo entre el concepto de muerte de la metafísica y la posibilidad de una praxis política anárquica. El artículo se compone de tres partes: en la primera se examinará la noción de Ser y de "a priori práctico" en el trabajo de Schürmann. En la segunda se verá la diferencia entre el nihilismo del autor y el de Vattimo, y en la tercera, se profundizará en las consecuencias más propiamente políticas del pensamiento de Schürmann.

Palabras clave: metafísica, ontología, anarquía, Schürmann, Heidegger, Vattimo, Kehre, épocas, fundamento.

\begin{abstract}
The article tries to approach the way in which Reiner Schürmann work, through an original interpretation of Martin Heidegger thought, manages to develop an anarchic political philosophy. We will try to analyse, in the dispersed work of the Dutch philosopher, the idea of anarchy as an existential condition, with special reference to the link between the death of the metaphysics and the possibility of an anarchist political practice. The article is divided in three parts: in the first part we will examine the notion of Being and of "practical a priori" in the work of Schürmann. In the
\end{abstract}


second, we will see the differences between Schürmann's and Vattimo's nihilism and, in the third, we will deepen the more properly political consequences of Schürmann thought.

Keywords: metaphysics, ontology, anarchy, Schürmann, Heidegger, Vattimo, Kehre, epochs, ground.

La fatalidad posee una cierta elasticidad que se suele llamar libertad humana.

Charles Baudelaire

\section{Hacia una ontología anárquica: topología del ser y a priori práctico}

El ex sacerdote dominico y pupilo de Hannah Arendt Reiner Schürmann es quizás el intérprete heideggeriano más original y el que más ha sabido vislumbrar imprevisibles consecuencias políticas en la obra del maestro ${ }^{1}$. Sin embargo Schürmann, a diferencia de otros estudiosos del filósofo, elabora una línea investigadora autónoma, recorriendo sendas escondidas del pensamiento de Heidegger que ni siquiera éste parecía saber que existieran. Sendas que Schürmann reanuda, dibuja y recorre justo allí donde Heidegger las había dejado interrumpidas. Schürmann entonces, se remite al pensamiento heideggeriano al mismo tiempo que se toma la libertad de alejarse de ello para insertar su propia filosofía. Esta lectura, a la vez fiel y traidora, de la obra del maestro le permite a Schürmann leer a Heidegger más allá de Heidegger, y sacar de ello consecuencias imprevistas, especialmente de carácter político. El resultado es un híbrido hermoso, en el que las raíces del pensamiento heideggeriano se pierden en las ramas de la libre interpretación de Schürmann, acabando por confundirse con ellas hasta un punto en el que ya no se distingue dónde termina de hablar Heidegger y donde empieza a argumentar Schürmann. Sin duda, esta especie de fiel infidelidad "libera" a Schürmann, como nos dice Reginad Lilly, traductor de Les Hégémonies Brisées, del papel de simple intérprete de Heidegger para erigirlo en pensador independiente y audaz 2 .

La principal novedad que el pensador holandés aporta a la lectura de Heidegger es la ruptura del paradigma interpretativo tradicional, que divide la filosofía del

\footnotetext{
1 Aunque ampliamente citado como comentarista de la obra de Martin Heidegger, en España el trabajo de Reiner Schürmann aún no ha sido objeto de un estudio exhaustivo. Al día de hoy, las únicas monografías dedicadas a este autor se encuentran en italiano: Martinengo, A.: Introduzione a Reiner Schürmann, Roma, Maltemi, 2008; y francés: Vaisse, J.M.(ed.), Autour de Reiner Schürmann, Hildesheim, Olms, 2009.

2 Lilly, R.: "The Topology of Des Hégémonies Brisées", Research in Phenomenology, n. 28, 1998, p. 226-242, p. 231.
} 
maestro en dos fases distintas: la primera, centrada en la analítica existencial, y la segunda (mucho menos precisa), recogida alrededor del "pensamiento sobre el ser" 3 . De hecho, según las lecturas convencionales, sería posible dividir el pensamiento heideggeriano en dos periodos distintos, cuya cesura es el gran proyecto inacabado de Heidegger, Sein und Zeit (1927). Dicha visión, no desprovista de buenas razones, bifurca la filosofía heideggeriana en dos etapas consecuentes, en las que se asiste a un pasaje, como nos dice Andrés Oses-Ortiz, "de una visión del ser enmarcado en el mundo del hombre, a una visión del ser que enmarca al hombre y a su mundo" 4 . Así pues, esta "primera fase" de la filosofía heideggeriana sufre de una cierta preponderancia, de una cierta "inflación" de la figura humana que destaca entre los otros entes y parece la verdadera protagonista de Ser y Tiempo. Casi se vislumbra, en esta fase, una "bajada" del ser hacia (o mejor, a través del) hombre, como si aquel se ensuciara inmanentizándose y éste resplandeciera con una nueva luz, ganando algo más que su simple "ser hombre". En Ser y Tiempo, el juego ser/Dasein se inclina hacia una relevancia del hombre en cuanto condición que posibilita el acontecimiento temporal del ser, que se radica sólo gracias al hombre gravitando en el tiempo existencial humano. Eso quiere decir que el propio ser no es en sí mismo, sino que se da en cuanto el Dasein le permite manifestarse o, según la hermosa expresión heideggeriana, le guía como "pastor del ser"5. Por otra parte, si es incontrovertible que el concepto universal de ser trascienda todo ente concreto, tampoco se le puede comprender a menos que reduzcamos metódicamente el problema ontológico de la existencia humana a la última fuente y fin del interés ontológico. El hombre y el ser se co-pertenecen, porque si por un lado el ser necesita del hombre para revelarse o manifestarse, por el otro el Dasein necesita aún más radicalmente del ser para poder ser. En otras palabras, el ser determina al ente en cuanto ente, y no en un sentido óntico (es decir como característica que "pega" al ente) sino como su propia condición de posibilidad. La comprensión del ser se da entonces en el Dasein como característica de su modo de ser, le pertenece al ser del Dasein como "lugar" en donde se puede alumbrar el sentido del ser, como bien apunta el propio Heidegger cuando dice que "la comprensión del ser es, ella misma, una determinación del ser del Dasein"6. Esta visión de interdependencia entre el ser y el Dasein, así como el estudio del sentido (Sinn) del ser a partir del ser-ahí7 vira-

3 Carchia, G.: "Introduzione”, en R. Schürmann: Dai principi all'Anarchia. Essere e agire in Heidegger Milano, Il Mulino, 1995.

4 Ortiz-Oses, A.: Heidegger y el ser sentido, Bilbao, Universidad de Deusto, 2009, p. 20.

5 Heidegger, M.: Caminos de Bosque (trad. Arturo Leyte y Helena Cortés), Madrid, Alianza, 2010, p. 259.

6 Heidegger, M.: Ser y tiempo (trad. Jorge Eduardo Rivera), Santiago de Chile, Editorial Universitaria, 1997, p. 35.

7 Así José Gaos, primer traductor de Sein und Zeit al castellano, traduce el alemán Dasein. Véase Heidegger, M.: El ser y el Tiempo (trad. José Gaos), México, Fondo de Cultura Económica, 1951. 
rá, a comienzos de los años treinta, hacia aquel giro conceptual del pensamiento heideggeriano conocido como Kehre, que agudizará la reflexión alrededor del tema del nihilismo. Esta "ruptura en la continuidad" tendrá su principal punto de inflexión en la lectura de Nietzsche (marginal en Ser y Tiempo) que se convertirá en la referencia filosófica fundamental para Heidegger, hasta el punto de engendrar una profunda crisis no sólo filosófica, sino también personal ${ }^{8}$. Nietzsche se convierte en la ocasión y el pretexto para un repensar el tema del ser, que ahora ya no es pensado en su inextricable relación con el ser humano, como en Ser y Tiempo, sino "por sí sólo", autonomizado con respecto a los entes mundanos. Evidentemente, esta elección no remite a una "actitud" del ser (afirmar esto significaría recaer en la dicotomía kantiana entre un fenómeno accesible y un noúmeno desconocido e incognoscible) sino más bien a un cambio de perspectiva en su estudio, como se pondrá de manifiesto con la publicación de trabajos como Vom Wesen der Wahrheit (1928) y Was ist Metaphysik? (1929). Aquí asistimos a una clara inversión de la relación serhombre. Si la finalidad de Ser y Tiempo era la búsqueda del ser a partir de aquel ser particular que es el hombre, la fase de la Kehre escoge una perspectiva que pretende alumbrar "la otra cara" de la investigación acerca del sentido del ser (que siempre había sido el objetivo prioritario de la investigación heideggeriana). En pocas palabras, ahora ya no se intenta entender el ser a través del ser del hombre, sino el ser a partir del ser mismo, es decir se piensa el hombre en relación al ser y no como antes el ser en relación al hombre9.

Ahora bien: según Schürmann tal bipartición no rendiría la debida justicia a la complejidad del pensamiento heideggeriano y se apaciguaría en la idea de que la analítica del Dasein encuentre su natural cumplimento en la Kehre de los años treinta, a través del abandono de los residuos humanísticos, y por esto metafísicos, que aún caracterizaban el Heidegger de Ser y Tiempo. Tal lectura sólo reduciría el pensamiento heideggeriano a un hecho evolutivo (y por ende historicista) ignorando con ello las verdaderas intenciones del autor. En cambio, la "revolución" que propone Schürmann consiste en una inversión de la tradicional interpretación cronológico-lógica de los textos heideggerianos. Pues sería preciso ver, según el pensador holandés, el Heidegger de Ser y Tiempo a la luz del último Heidegger y no el revés. Se trata de un verdadero cambio de rumbo y no de un simple giro en el orden de los sumandos para averiguar si el resultado no cambia. Con ello Schürmann pretende sacar a la luz una serie de asuntos tradicionalmente ignorados en las clásicas interpretaciones convencionales-evolutivas. De hecho, reconsiderar las divisiones temporales del pensamiento del maestro no sólo redimensiona la envergadura de la ana-

\footnotetext{
8 "Tengo la sensación de creer ahora sólo en las raíces, ya no más en las ramas" dice Heidegger en una conversación con Karl Jaspers y, con sus amigos: "Nietzsche me ha destruido", Volpi, F.: El nihilismo (trad. Cristina I. del Rosso y Alejandro Vigo), Buenos Aires, Editorial Biblos, 2005, p. 106.

9 Leyte, A.: Heidegger, Madrid, Alianza Editorial, 2006, p.165-71.
} 
lítica existencial, generalmente considerada la clave de bóveda para una lectura de la obra entera de Heidegger, sino que introduce también una tercera fase de su filosofía. Esta consistiría en una radicalización del anti-humanismo en el interior de la Kehre, que de éste modo se bifurcaría a su vez en una segunda rama. Por ello ya no se podría hablar simple y sencillamente de la Kehre como de un bloque monolítico y homogéneo, ya que se trataría de una "ruptura en la ruptura", casi una segunda Kehre o una post-Kehre. Explicar la existencia del "tercer" Heidegger es el intento (de cuya dificultad Schürmann es muy consciente) de su obra principal Heidegger on Being and Acting. From Principles to Anarchy (1982), donde el autor busca cautelosamente motivar la existencia de esta tercera fase del pensamiento heideggeriano, escondida y sin embargo determinante ${ }^{10}$. Este tercer momento, además de la analítica de la primera fase y del anti-humanismo y la relectura del sentido del ser en clave epocal de la segunda, configura una despresencialización radical del ser, que no sólo pierde la fuerte relación que tenía con el Dasein en la fase de Ser y tiempo, sino que supera también la declinación histórico-temporal de la epoché del segundo Heidegger. La tercera fase desmoronaría por completo los vestigios presencialistas que el ser conservaba en el darse temporal en el interior de cada época, para diluirse enteramente en el puro acontecimiento "sin un por qué", en el Ereignis (un deslizamiento éste que, según Schürmann, pasa casi inadvertido al propio Heidegger) ${ }^{11}$. Refiriéndose a este cambio, Schürmann recupera la expresión heideggeriana "topología del ser", indicando con ésta aquella pluralidad irreductible de "lugares" donde el ser acontece:

En Heidegger, [topoi, lugares], son las épocas de nuestra historia que han precedido a la edad de la técnica. La topología enseña las profundas raíces históricas del alcance global de hoy día. Como ella traza los lugares que han sido nuestros, que son nuestros, y pueden ser nuestros, ella es recapituladora, crítica y anticipadora. ${ }^{12}$

Los topoi son entonces los lugares históricos en los cuales estamos situados, arrojados (Geworfenheit) para usar el vocabulario heideggeriano, en los que el ser

\footnotetext{
10 El texto original fue escrito en francés: Schürmann R.: Le principe d'anarchie: Heidegger et la question de l'agir, Paris, Seuil, 1982. Sin embargo, en este escrito utilizaremos la traducción al inglés revisada por el mismo autor: Schürmann R.: Heidegger on Being and Acting. From Principles to Anarchy, Bloomington, Indiana University Press, 1986.

11 Ibidem, p. 140. Nótese que el tema del Ereignis es objeto de investigación en Heidegger, M.: Aportes a la filosofia: acerca del Evento (trad. Dina V. Picotti C.), Buenos Aires, Biblos, 2006. Cfr también Heidegger, M.: Gesamtausgabe, band 67: Metaphysik und Nihilismus, Frankfurt am Main, Vittorio Klostermann, 1999.

12 Schürmann, R.: "Technicity, topology, tragedy: Heidegger on "That Which Saves" in the global reach", en A.M. Meltzer: Weinberger J.: Zinman M.R.: Technology in the Western Political Tradition.: N.Y.: Cornell University Press, 1993, p. 196.
} 
"se da" (es gibt), es decir los horizontes históricos y lingüísticos en los que el ser viene a la luz, pero sin que estas figuras tengan algo de definitivo o estable. Más bien lo contrario, ya que la ausencia de fundamento es la única cosa estable de cada época ${ }^{13}$. Hasta aquí nada nuevo si se piensa que el propio Heidegger llama la última fase de su pensamiento la "topología del ser"14 y un heideggeriano de la primera honrada como Otto Pöggeller dice:

El pensar localizador, topológico, intenta algo bien simple: lo que busca es utilizar el lenguaje de manera meditada. Tal pensar hace que se atienda al hecho de que nuestro lenguaje está determinado por presupuestos que siguen estando impensados $\mathrm{y}$, como topología del ser, pregunta qué sea aquello que nosotros, hombres occidentales, mentamos propiamente cuando decimos "es". El pensar topológico medita sobre el hecho de que nosotros, al hablar como lo hacemos, nos insertamos en un lugar determinado en el acontecer de la verdad; tal pensar no dona lo propio en el sentido de lo único verdadero, como si fuera lo único correctamente adecuado a lo constantemente verdadero, sino que lo confía al suelo natal de la localización ulterior. ${ }^{15}$

Lo mismo nos dice Vincenzo Vitiello cuando indica que el pensamiento heideggeriano sufre un desplazamiento de la hermenéutica, aún atrapada en una herencia metafísica, a la topología del ser, que recupera el trasfondo de la fenomenología eidética husserliana:

El trazado, o mejor, los múltiples trazados que describe la topología forman el mapa de los lugares "ideales", los tópoi, del ser. Esos tópoi son las épocas: figuras históricas, no sucesos o momentos; no períodos de tiempo ni hechos que surgen y perecen, sino figuras ideales, esencias, eidé. Comprender históricamente es llevar el hecho al eidos. ${ }^{16}$

Pero la novedad, para nada secundaria, que introduce la reflexión de Schürmann, es una marcada preeminencia de la dimensión subjetiva del acaecimiento del ser. Leámoslo directamente:

En términos topológicos, nos hallamos inscritos en el interior de un horizonte, un "tiempo-espacio", y luego de inmediato reinscritos en otro. Esta perplejidad atañe únicamente a los particulares: una terra deserta que ya no es nuestra, y una transición en la que una colectividad entera vive como si contuviera la respiración. Ningún nomos seguro

\footnotetext{
13 Schürmann, R.: Heidegger on... op.cit.: p. 142.

14 Véase Heidegger, M.: Seminario en Le Thor, (trad. Diego Tatián), Córdoba, Alción Editora, 1995.

15 Pöggeller, O.: El camino del pensar de Martin Heidegger (trad. Félix Duque), Madrid, Alianza Editorial, 1993, pp. 357-358.

16 Vitiello, V.: "Historia, naturaleza y redención", en F. Duque: Los confines de la modernidad. Diez años después de Heidegger, Barcelona, Granica, 1988, p. 47.
} 
gobierna este nomadismo donde los sitios y las plazas (allocations and assignments) van hacia planes discontinuos. ${ }^{17}$

El darse del ser nada más que como ausencia de fundamento engendra entonces una "perplejidad que atañe a los particulares". Con lo cual, la cuestión del ser está vinculada con la experiencia subjetiva, la "de los particulares" que se encuentran arrojados en una apertura histórico-destinal del ser. El pensador holandés intenta por lo tanto superar la rígida dicotomía ser/Dasein presente en la primera fase del pensamiento heideggeriano, y en su lugar propone una lectura más orgánica de dicha relación, donde el particular-Dasein encuentra el ser como total ausencia de fundamento. Al respecto, tiene razón Lilly cuando dice que Schürmann, en su estudio sobre la topología del ser, pretende ahondar en un aspecto nada marginal del pensamiento heideggeriano, es decir, la conexión entre analítica existencial e historia del ser como onto-teología (una problemática que jamás fue esclarecida por Heidegger o sus comentadores). En pocas palabras, Schürmann nos brinda aquellos elementos, estructuras, dinámicas que son fundamentales para la existencia humana y que son presupuestos de toda filosofía de la historia18. La lectura "al revés", desde la post-Kehre a la analítica existencial, tiene entonces el efecto de liberar el Dasein de un ser pensado como ontología estable y presencia fija. Pero este entendimiento del ser como fundamento infundado es sólo el punto de llegada de un proceso más amplio que encuentra en el sujeto, en su carácter trágico-existencial, el verdadero actor ${ }^{19}$.

Ahora bien, Schürmann sugiere que es posible pensar el ser como Ab-grund, como ausencia de fundamento solamente, por decirlo así, aceptando una cierta actitud existencial que nos permita vivir, sufrir, y padecer dicha falta. El Dasein, en su estado de arrojado, percibe la inconsistencia de las economías de la presencia, su desvanecimiento temporal, su mutabilidad continua, es decir su anarquía. Se trata, como es evidente, de una noción de anarquía en cuanto condición existencial y no como dirección política, y sin embargo inseparable de un discurso más propiamente político strictu sensu. Pues la noción de anarquía a la que se refiere el filósofo holandés es un hecho personal individual, una especial actitud hacia la vida o, en sus propias palabras, un "a priori práctico":

para entender auténticamente la temporalidad, es menester "existir auténticamente"; para pensar que el ser deje ser a los fenómenos, uno debe por sí mismo "dejar que las

\footnotetext{
17 Schürmann, R.: Technicity, topology... op.cit.: p. 198.

18 Lilly, R.: op.cit.: p. 233.

19 Schürmann no es un existencialista y sin embargo toda su obra hace constante hincapié en el papel del ser humano y en su radical libertad con respecto a la muerte de la metafísica.
} 
cosas sean"; para seguir el juego sin el por qué de la presencia, es necesario "vivir sin un por qué."20

El mismo concepto lo vemos reafirmado repetidamente a lo largo de todo el trabajo de Schürmann. La piedra angular es la idea según la cual "una manera de pensar es dependiente de una manera de vivir"21. Este "a priori práctico" estaría presente, según Schürmann, tanto en el primer como en el segundo Heidegger. En su análisis de Ser y tiempo el autor, preguntándose acerca de "qué es lo que entraña la trascendencia del Dasein", contesta: "una especial manera de comportarse, una cierta actitud de su ser en el mundo, la inautenticidad", y agrega que en "en Ser y Tiempo, las ontologías clásicas brotan justamente de la existencia inauténtica". En conclusión, todo esto:

indica ante todo y sobre todo que la apropiada recuperación de la cuestión del ser está destinada al fracaso si no va precedida por lo que [Heidegger] llama una modificación existenciaria [...] primero llega una apropiación de las posibilidades existenciales, y luego una ontología existencial.22

El "a priori práctico" es sobre todo un método empírico más que una guía teorética, una praxis más que una teoría. Se trata de una actitud que nos conduce desde una manera de vivir hasta una manera de pensar, que da prioridad a la vida individual y diaria sobre la teoría política. No se puede, en otras palabras, pensar la anarquía sin antes haberla vivido como condición existencial. Abrazar la anarquía pues, no significa adherirse a un sistema de pensamiento riguroso o académico, sino que es una manera de concebir la existencia diaria (también en el lenguaje común se dice "tener una filosofía" para indicar una visión general, una Weltanschauung del mundo). Al respecto, Schürmann es lapidario:

La inseguridad, signo del nihilismo es, por lo tanto, antigua en Occidente. El pensamiento occidental plantea la cuestión de la razón de lo que es. Pedir cuentas de lo real, dar razón, exigir un "por qué" último, es la actitud característica de lo que Heidegger llama la 'metafísica'. La filosofía en general ha surgido de este instinto: encontrar un fundamento verdadero que amarre todas las cosas y que tranquilice al "corazón inquieto". 23

Con un toque algo antropológico, el autor indica la necesidad de seguridad en el nacimiento de la metafísica, insuperable obstáculo a la anarquía existencial. Pero

\footnotetext{
20 Schürmann, R: Heidegger... op.cit, p. 287.

21 Ibidem, p. 237.

22 Ibidem, p. 237-238.

23 Schürmann, R.: Tres "pensadores del abandono": Meister Eckhart. Heidegger Susuki, Córdoba, Paideia, 1995, p. 54.
} 
¿cómo es posible, en la praxis, vivir la anarquía? Es decir ¿cuáles son las condiciones que permiten a cada cual volverse anárquico, entender el sin fundamento de su propia vida y (de ahí) de las constelaciones de sentido en las que se encuentra arrojado? La respuesta de Schürmann gira alrededor de la noción heideggeriana de diferencia ontológica, que cobra todo su sentido sólo si se la lee a la luz del anti-humanismo del segundo (y sobre todo tercer) Heidegger. Aquí el ser y el hombre se despegan, por así decirlo, como "exigencia" interior al mismo ser. Para que este último se temporalice en onto-teología, ha de perder todo enlace con el ser humano. Es decir, para pensar el ser como tiempo ya no es necesario remitirse a la temporalidad humana y entonces mantener viva aquella especial relación privilegiada entre el ser y el Dasein. Pero una vez que el ser se haya reducido a evento, este ya no tiene un sentido último (ya no es un faro para el ser humano), sino que sólo acontece sin un por qué, sin ser depositario de una verdad última y escondida, ya que el evento se da en la contingencia y nada más. Según Schürmann, la lección del maestro alemán sería entonces desprender el sujeto-Dasein de un referente último (el ser) que oriente y dirija sus acciones. Como nos recuerda la cita anterior, según Schürmann la metafísica (y sus intentos tranquilizadores) trae fuerza precisamente de la inseguridad existencial que todo hombre sufre en tanto que arrojado24. Pero una vez que el ser humano acepte esta inseguridad, aprendiendo a "vivir sin un por qué", se libera de la carga del ser. Él pierde finalmente su papel "sagrado" de pastor del ser y se convierte en "uno de los elementos... del juego autónomo del mundo"25. Pues, si un ser pensado como presencia estable y objetividad indisoluble gravaba sobre el ser humano, en cambio un ser pensado como evento le alivia de toda carga:

el Ereignis es lo que nos establece en nuestras residencias precarias, no como algo, sino como nada, el mero venir para pasar (coming to pass). ${ }^{26}$

En conclusión: el acontecer del evento es independiente del ser humano, que ya se encuentra arrojado en una determinada época histórica, en una constelación de sentido. Por esto, Schürmann "transforma" la analítica existencial en analítica epocal: cuando Heidegger descubre que la vida cotidiana tiene una historia, que el ser en el mundo de los antiguos griegos no es lo mismo que el de un hombre que vive en la sociedad tecnológica, entiende que las metafísicas (el plural es significativo) son tentativas, en última instancia siempre fracasadas, de absolutizar lo que siempre es temporal e histórico. Por ejemplo, el arché de la Edad Media puede decirnos cómo vivían los hombres y las mujeres medievales, pero no cómo tenemos que vivir nosotros, porque aquel arché ya se ha perdido. Es precisamente éste el

\footnotetext{
24 Schürmann, R.: Heidegger... op.cit.: p. 56.

25 Ibidem, p. 211.

26 Ibidem, p. 57.
} 
sentido de la pregunta de Schürmann sobre Duns Scoto: ¿por qué el filósofo, apodado incluso Doctor Subtilis, no logró escribir una Crítica de la razón pura o una Genealogía de la moral? Porque la filosofía, esto es, el pensamiento, es comprensible a sí mismo como una sucesión de distintas épocas de pensamiento, según paradigmas históricamente colocados. Si se puede afirmar entonces que el pensamiento está determinado por principios epocales, lo mismo pasa con el ser, al cual el pensamiento está vinculado. Con lo cual, la realidad misma siempre se despliega según "economías históricas de la presencia", hegemonizadas por la huella metafísica vigente. Desde este punto de vista, cada metafísica es soberana con respecto a todo lo que compone como una constelación de la presencia, discriminando, si queremos, lo que es "moral", "posible", "justo", de lo que no lo es. Es evidente entonces que Duns Scoto no podía pensar fuera de su época, es decir de su moral, de su cultura, de su concepción de la justicia etc. Las metafísicas, en otras palabras, intentan establecer unos principios objetivos (y por ende eternos) allá adonde no hay nada más que contingencia 27 . Vivir la anarquía significa entonces cobrar conciencia de esta "discordancia epocal", que podemos comprender (como ya había entendido Heidegger) en la vida diaria, donde el ser "sale a luz" precisamente como falta de fundamento:

Si el ser (presencing-being-) es comprendido sólo a través de la diferencia con la presencia epocal, entonces nuestra experiencia diaria del ser está perdida para siempre (lost forever) en cuanto un nuevo pliegue (fold) despliega (unfurls) una nueva constelación.28

\section{La discordancia epocal y la polémica con Gianni Vattimo}

Veamos ahora cómo es posible en la práctica que esta anarquía, esta toma de conciencia de la nada que nos forma, pueda liberar al hombre de los pesares de la metafísica. La filosofía, argumenta Schürmann siguiendo a Heidegger, ha estado preocupada desde siempre por explicar lo que es, su arché y su télos, confundiendo al ser tanto con la totalidad de los entes como con el ente supremo, y dejando pasar en silencio la cuestión del ser mismo, lo impensado de la tradición filosófica. La filosofía tradicional habla del ser "en tanto que ser" sólo con el fin de poder pensar mejor el ente (Dios, la totalidad del mundo, el sujeto, el espíritu). El desvanecimiento que horroriza a nuestro siglo y que lo lleva a buscar certidumbres tranquilizadoras es algo más que la pérdida de una pieza del universo: falta el ser mismo. Pero al mismo tiempo Schürmann comparte con Heidegger la idea de que la sociedad en la cual vivimos, la sociedad tecnológica, lleva al ocaso la metafísica y muestra lo

\footnotetext{
27 Idem.

28 Ibidem, p. 158.
} 
infundado de todos los principios pasados. Ella inaugura una época donde los viejos archai son finalmente aniquilados y extintos, y se abre al origen anárquico del ser como simple presencia. Porque si la época "abandonada por el ser" es una era de más de dos milenios, el siglo tecnológico es sin duda el más abandonado de $\operatorname{todos}^{29}$. Según el autor holandés, esto da vida a un tipo distinto de praxis, una praxis anárquica ya que "para legitimar la praxis, ya no hace falta referirse a un primer fundamento, a una suprema razón, a un fin último o una última finalidad"30. La liberación de la que nos habla Schürmann es entonces la liberación del fundamento, y tiene una validez tanto filosófica como política. Filosóficamente, es la liberación de los fenómenos de un referente superior, es decir, la actitud que deja "que las cosas sean". Políticamente lleva como emblema la figura del filósofo rebelde (Schürmann recuerda a Sócrates), que se substrajo a los imperativos de su época porque, una vez que se haya introducido una cierta fluidez en las instituciones sociales, así como en la práctica, es menester rebelarse contra todo principio o construcción superior 31 . Intentaremos ahora tratar los dos asuntos, el filosófico y el político, por separado, pero en la convicción de su vínculo constitutivo.

Primero el filosófico, que gira alrededor de la noción de abandono del ente por parte del ser (es el ser quien abandona) y que explica cómo el hombre puede lograr finalmente liberarse de la tiranía del fundamento. Siguiendo a Heidegger, Schürmann argumenta que no se entendería verdaderamente la naturaleza del ser si a su concepción positiva, es decir el ser como época, no se le acercara su cara negativa y contraria. Esta última noción está inscrita en la misma etimología de la palabra epoché (suspensión), como lo que está suspendido, como disponibilidad de lo que es partiendo de lo que no es. Es decir, no basta con afirmar que el ser es época, ya que ésta puede ser igual de objetivadora que la metafísica. Al fin y al cabo no se destruye la metafísica con sólo hacer del ser una variable histórico-temporal, en cuanto ésta seguiría manteniendo un sentido fuerte, presencial, estatutario dentro de cada época (ésta es además la razón de la polémica, que reproducimos más abajo, con Gianni Vattimo). En cambio Schürmann se interroga sobre el origen de las épocas de forma original, como confirma el mismo título de su obra, en la que acerca el término Principio al de Anarquía. Este aparente oxímoron quiere precisamente indicar el fundamento infundado de cada fundamento metafísico. El acontecer del ser, el Ereignis, no tiene otro fundamento (otro principio) que la anarquía (la falta de principios). Se trata de una dimensión de tipo "vertical". Es decir, el trasfondo estable que subyace a cada época, aquella base o principio que da sentido a la presencia de los entes, es justo la substancial falta de fundamentos: la anarquía. Pero paradójicamente decir que la anarquía es origen quiere decir que no hay origen

\footnotetext{
29 Ibidem, p. 190-192.

30 Ibidem, p. 281.

31 Idem.
} 
alguno. El autor esclarece este concepto remitiéndose a la distinción clara y fundamental entre el origen, entendido en singular, como metafísica del arché, y los orígenes en plural como principios fundadores de las distintas metafísicas (éticas, políticas, identitarias, etc.). Detrás de los orígenes como principios está siempre el origen como fundamento infundado de todo lo que hay. El descubrimiento de este origen infundado sería la verdadera novedad del Heidegger maduro, en el cual se podría tranquilamente hablar de una ontología del evento aligerada de cualquier legado substancial. En conclusión: en su relectura de Heidegger, Schürmann elimina toda traza de mitología del ser o de una visión "auroral" de los orígenes. Si el Ereignis, entendido como origen del ser, es el principio de refutación de cualquier otro principio, hay que sustituir el fundacionalismo por aquella noción que ya en el vocabulario heideggeriano era el "dejar ser" (Gelassenheit) de los entes ${ }^{32}$. En otras palabras, si las épocas son los contextos en cuyo interior los entes se llenan de sentido, este "llegar al ser" de un mundo de sentidos no tiene ninguna otra razón sino en el darse puro y simple del evento: "en un fenómeno entendido como a través del dejar-ser, el fundamento se enseña como nada más que lo que deja ser" 33 .

Esta nada del ser se vuelve evidente en la diferencia ontológica, que revela la duplicidad o ambigüedad (Zweideutigkeit, Zwiefalt) interna al mismo ser:

En Heidegger la diferencia ontológica significa que el ser se muestra como pasaje hacia el ente. El ser no es él mismo, y el ente no es él mismo más que en el pasaje. El ser se ampara en esta llegada, se hace presente asignándole su lugar al ente. El ser deja ser al ente. 34

El ser entonces abandona (Anwesenlassen) el ente, lo deja ser. El abandono abre la diferencia ontológica entre el presente y su presencia. Sin embargo, no hemos de entender el abandono sólo como una actitud del hombre, sino como una "apertura sin condición" donde los entes aparecen en tanto que entes. En este sentido, Schürmann interpreta correctamente la relación que, en De la esencia de la verdad, Heidegger instaura entre verdad y libertad, o mejor la verdad como libertad. Mientras que en Ser y Tiempo la libertad era definida como un poder-ser y, en última instancia, como libertad para la muerte, ahora la libertad es el dejar-ser. El hombre libre deja que el ente se revele por lo que es, en tanto que se compromete con el desocultamiento (lo verdadero). Pues el dejar ser marca el pasaje del ente del estatus de no-ser al de ser y éste es el único fundamento posible, un fundamento totalmente infundado en cuanto no tiene ningún principio detrás de él. El ser, pen-

\footnotetext{
32 Ibidem, pp. 132-140.

33 Schürmann, R.: "The ontological difference", Philosophy and Phenomenological Research, vol. 40 n. 1, sept 1979, pp. 99-122, cit. p. 113.

34 Schürmann, R.: Tres "pensadores... op. cit, p. 57.
} 
sado por sí mismo, significa el hundimiento de todo apoyo. Ello no pone nada, no se pone por debajo del ente como su base (por tanto no supone nada) y tampoco precede al ente como su causa (por tanto no presupone nada) ${ }^{35}$. Se entiende por lo tanto que la verdadera novedad del segundo/tercer Heidegger sería el descubrimiento de una anarquía originaria, merced a la cual el evento, en lugar de fundar los fenómenos, sólo los deja ser, los abandona a la presencia. La libertad (de dejar ser) es entonces la condición de posibilidad de la verdad. ¿Cómo no ver en esto una invitación a un anarquismo existencial por el que ser libre significa, primero y ante todo, "dejar ser", renunciar a cualquier afán fundacional?

Ahora bien: la consecuencia más evidente de dicha desfundamentación del origen es la muerte de la tradicional primacía del pensamiento sobre la realidad, objetivo declarado ya desde las primeras páginas de From Principles to Anarchy. La vieja unidad entre pensar y actuar pierde cohesión cuando el pensar mismo ya no quiere proveer un fundamento racional sobre el que disponer el conjunto de lo conocible. De la misma manera, el actuar ya no consiste en ajustar la conducta diaria, pública y privada, a algún mítico fundamento. Más bien la ausencia de un arché pone en entredicho el carácter último y definitivo del modelo tradicional de gestión de la praxis. Pero desprender la acción de todo fundamento racional significa liberar la praxis de su tradicional subordinación respecto del pensamiento y de las construcciones absolutas de sentido. Por lo visto hasta aquí, la gran novedad de la lectura heideggeriana que nos proporciona Schürmann no estriba tanto en la asunción de la total falta de fundamentos en el ser, sino en las consecuencias prácticas y existenciales de dicha ausencia. Sólo viviendo el nihilismo y asumiendo la falta de un trasfondo metafísico estable, es decir, sólo desacostumbrándonos a vivir según las legitimaciones corrientes, los confortables valores que desde siempre han regido nuestra vida, es posible de verdad producir un pensamiento del evento (Heidegger habría dado, de esta manera, la preeminencia a la praxis sobre la teoría) ${ }^{36}$.

Se nota una diferencia muy marcada entre la interpretación de Reiner Schürmann y la de otro gran lector de Heidegger, Gianni Vattimo ${ }^{37}$. También para este último el ser se da como apertura histórica u horizonte en el que las cosas, los entes, vienen al ser (una corriente artística, un régimen político, una gran experiencia religiosa, etc.). El ser pierde su carácter fundador para volverse trayecto histórico, es decir múltiple, imprevisible, irreductible a cualquier forma de racionalidad etc. ${ }^{38}$. La lectura ya de por sí bastante liberadora (y libertaria) de Vattimo, es radi-

\footnotetext{
35 Idem.

36 Schürmann, R.: Heidegger... op.cit.: pp.33-38.

37 Se elige comparar Schürmann con Vattimo, no sólo por el debate que los dos tuvieron acerca del tema, sino también porqué las dos interpretaciones se acercan en su común intento de dar una lectura "libertaria" de Heidegger.

38 Véase especialmente Vattimo, G.: Introducción a Heidegger (trad. Alfredo Báez), Barcelona, Gedisa, 1992.
} 
calizada por Schürmann, que llega a negar todo fundamento metafísico a las épocas. De hecho, comentando la lectura que Schürmann hace de Heidegger y comparándola con la suya propia, Vattimo ve la diferencia en el hecho de que, mientras para él el ser se da sólo en la ausencia, como huella, y se puede hablar de ello sólo una vez que ya haya ocurrido, para Schürmann en cambio la anarquía sería una especie de anuncio "positivo" del ser como no-fundamento ${ }^{39}$. Por su parte, el propio Schürmann subraya la diferencia con respecto a Vattimo en un artículo de 1984, titulado Deconstruction is not enough donde reprocha al pensador italiano la contradicción de intentar tematizar simultáneamente el evento de la presencia, que escapa a la representación, y los valores, que son la representación par excellence ${ }^{40}$. La cuestión, sospechamos, es política más bien que filosófica y levanta interrogantes sobre la propuesta de Vattimo de abordar un tipo de revolución pos-metafísica o, en el lenguaje del propio Schürmann, establecer de qué sexo es el ángel de Paul Klee. Esta última imagen, de memoria benjaminiana, había sido usada por Vattimo para indicar la actitud del hombre (post)moderno frente a la metafísica, como aquel que contempla piadosamente las ruinas (metafísicas). Para Vattimo la superación de la metafísica sería a su vez un acto presuntuoso y hegemónico, en cuanto imposición de una nueva y más "verdadera" metafísica. Más bien haría falta un dialogo con el pasado bajo la insignia de la pietas, esto es, recordar el ser en el hecho de haberse ya sustraído ${ }^{41}$. Recordar el ser y no olvidarlo o, como dice el propio Vattimo con una expresión heideggeriana, rememorarlo (Andenken):

el Andenken tiene el sentido de una reapropiación; no en el sentido propio de la fundamentación, sino en el sentido de la suspensión, a través de la desfundamentación, de las pretensiones de urgencia de los horizontes históricos particulares, que crean agotar el sentido del ser. 42

El pensamiento rememorante es un volver a la historia no con nostalgia o patéticas tentativas de hacer revivir el pasado en el presente, sino como un retomaraceptar-redirigir el pasado, una confrontación cuidadosa y piadosa con su herencia, caracterizada por lo que Vattimo denomina devoción-respeto hacia los monumentos. Esta devoción, como es evidente, sólo se puede dar cuando la metafísica haya dejado de ser ontos on y adquiera por esto valor de monumento 43 . Así pues, la tarea del pos-moderno no es la de deshacerse de una vez por todas de los escombros

\footnotetext{
39 Prefacio de G. Vattimo a Martinengo G.: Introduzione a Reiner... op.cit.: p. 10.

40 Schürmann, R.: "Deconstruction is not enough: on Gianni Vattimo's call for "Weak Thinking", Graduate Faculty Philosophy Journal, volume 10 n. 1, Spring 1984, pp. 165-177.

41 Vattimo, G.: Ética de la interpretación (trad. Teresa Oñate y Zubia), Barcelona, Paidós, 1991, p. 33.

42 Vattimo, G.: Más allá del sujeto (trad. Juan Carlos Gentile Vitale), Barcelona, Paidós, 1992, p. 104.

43 Vattimo, G.: Etica... op.cit.: p.29.
} 
modernos, desechando el pasado heredado, sino retomar la modernidad distorsionándola y vinculándose a ella por libre elección y ya no en base a un presencialismo decisionista. De esta manera la herencia moderna, liberada de las categorías metafísicas, adquirirá un valor monumental. Los vestigios, las ruinas, las huellas imborrables del pasado, han de ser miradas con la debida pietas que se les debe a los monumentos que han perdido finalmente su contenido fuerte y se "abren" a una pluralidad de interpretaciones ${ }^{44}$. Se trata de conciliar modernidad y pos-modernidad en un juego interpretativo inconcluso, abierto, lúdico, y relacionarse con el pasado ya no de modo adecuacional (como hace la metafísica) sino irónico, caprichoso, en un dialogo irreverente, secularizado, distorsionado y divertido. Finalmente, el Andenken acaba por sustituir el fundamento asumiendo "dentro del pensamiento pos-metafísico la función que era propia de la fundamentación metafísica" 45 .

Por su lado Schürmann se pregunta si este diálogo no estaría todavía empapado de metafísica o incluso sería totalmente inoperante. El pensador holandés vislumbra el riesgo de que el pensamiento débil esconda detrás de su máscara de debilidad una fuerza aún más brutal. Así como en el aforismo nietzscheano la debilidad es una invención de las mujeres para defenderse contra los fuertes, lo mismo haría el pensamiento débil que escondería una fuerza detrás de su máscara de debilidad. Schürmann afirma entonces que la debilidad del pensamiento vattimiano se parece más a la mala debilidad de las mujeres virilizadas, las feministas, que a la buena debilidad de la feminización de lo masculino, donde la primera es "mala" porque sólo reproduce más estándares universales, es decir más metafísica, mientras que la segunda es en cambio "buena" en cuanto transmuta estándares sin tiempo en mesuras radicalmente temporalizadas ${ }^{46}$. Schürmann, creemos, está reprochando a Vattimo su compromiso peligroso con la metafísica, su tentativa de mediar entre un pensamiento pos-metafísico y su actitud piadosa hacia las ruinas del pasado. De hecho ¿hasta qué punto esta piedad no se vuelve aceptación activa, tentativa de restauración de los monumentos? ¿Podría el pensamiento "débil" estar ocultando una fuerza igual de peligrosa que la vieja metafísica, que de hecho nunca abandona por completo? El filósofo holandés no quiere tropezar en la misma trampa de su colega italiano $\mathrm{y}$, tal vez a costa de una cierta traición al pensamiento heideggeriano, la evita aniquilando todo fundamento hasta el punto de considerar el mismo evento como totalmente carente de fundamento. Desgraciadamente la cautivadora polémica intelectual entre los dos autores quedó inconclusa por el prematuro fallecimiento de Reiner Schürmann en 1993. La cuestión sigue abierta.

\footnotetext{
44 Ibidem, p. 33.

45 Pero el Andenken tiene también a que ver con el Danken, el agradecimiento, lo del hombre por estar siempre abierto al acontecimiento del ser. Vattimo G.: Más allá... op.cit.: p. 103.

46 Schürmann, R.: “Deconstruction... op.cit.”, pp. 173-175.
} 


\section{Para una praxis política anárquica}

Pasando ahora al terreno político, la singular lectura "al revés" de Schürmann arroja una nueva luz sobre las relaciones entre Heidegger y el nazismo. ${ }^{47} \mathrm{La}$ tradicional lectura, cronológicamente lineal, veía en la analítica existencial un momento preparatorio para el famoso discurso de rectorado del año $33^{48}$, considerado por muchos como el manifiesto de adhesión de Heidegger al Tercer Reich hitleriano 49 . Pero una lectura "al revés" de los escritos heideggerianos permite sacar conclusiones totalmente distintas, donde Heidegger se opondría de manera radical al Führerprinzip, y promovería en cambio una ética pluralizante y disolvente de cada fundamento 50 . En un artículo de 1987 publicado en la revista Social Research, e inequívocamente titulado Political Thinking in Heidegger, Schürmann esclarece su interpretación política sobre el pensador alemán. Según él, el pensamiento de Heidegger, a pesar de que muchos de sus discípulos afirmaban que el maestro no estaba familiarizado con los asuntos estrechamente políticos, no se puede de ningún modo considerar desprovisto de una dimensión política ${ }^{51}$.

El discurso arranca desde un terreno ontológico para volverse rápidamente político. El punto de partida es la distinción entre diferencia ontológica metafisica y diferencia ontológica fenomenológica. Mientras la primera piensa el ser de los entes como un terreno fundador, la segunda en cambio diferencia el ser y los entes y muestra la preservación de ambas en un proceso de desocultamiento que las mantiene ocultas. Es decir, pensar la diferencia ontológica de forma metafísica impide cualquier perspectiva histórica en cuanto el fundamento es una conquista contra el devenir, la historia, el tiempo. Por el contrario, considerar dicha diferencia desde una perspectiva fenomenológica nos permite pensar en términos de proceso histórico, porque el ser de los entes es un modo, siempre nuevo, a través del cual aquél se da

\footnotetext{
47 Este tema nos sirve para poder entender mejor el pensamiento político de Schürmann y no para investigar la cuestión de las relaciones de Heidegger con el Tercer Reich.

48 El discurso ha sido recopilado en Heidegger, M.: Escritos sobre la universidad alemana (trad. Ramón Rodríguez García), Madrid, Tecnos, 1996.

49 Algunos autores han notado que las temáticas que Heidegger usa en el discurso del 33 ya estaban profundamente arraigadas en la analítica existencial de Ser y Tiempo (véase Harries, K.: "Heidegger as a Political Thinker", Review of Metaphyisics, n. 29, June 1976, pp. 642-669). La bibliografía acerca de las relaciones histórico-filosóficas entre Heidegger y su compromiso con el nacionalsocialismo es voluminosa; nos limitamos aquí a indicar dos trabajos de los más relevantes: el libro de Víctor Farias, Heidegger y el nazismo, Fondo de Cultura Económica, Buenos Aires, 1998; y el ensayo de Karl Löwith, sólo disponible en francés, Les implications politiques de la philosophie de l'existence chez Heidegger, Les Temps Modernes, Noviembre 1946.

50 Schürmann, R.: Heidegger... op.cit.: p. 80 e ss.

51 Schürmann, R.: "Political Thinking in Heidegger", Social Research, vol. 45, n. 1, Spring 1978, pp.191-221.
} 
en éstos. El paso del terreno metafísico al fenomenológico permite concebir el ser como algo distinto del principio universal de los entes (como la característica general de los entes específicos) y adquiere un carácter exclusivamente histórico, llámese physis, lógos, enérgeia, Subjetividad, incluso Tecnología, etc. (pero no es nada más que una modalidad temporalmente circunscrita a través de la cual el ser se da a los entes ${ }^{52}$ ). Ahora bien: la diferencia ontológica reformulada en un sentido fenomenológico se compone de tres elementos. Primero: la diferencia simbólica. Esta es el paradigma para entender la diferencia ontológica entre ser y entes, ya que el símbolo es por definición la evidencia de algo escondido (lo simbolizado) que ha de ser interpretado. Segundo: cierta actitud práctica (el famoso a priori práctico). Esto es necesario para que se entienda el símbolo, como si el ser humano estuviera casi "llamado" en su existencia por el propio ser a superar el símbolo. Por último, la pluralidad de símbolos, siendo la diferencia simbólica necesariamente polimorfa (no hay una diferencia uno a uno, sino unos a unos). Podemos decir que, así como la diferencia simbólica conecta el símbolo y el simbolizado (el verbo griego symballein tiene este sentido de "reunir"), de la misma forma la diferencia ontológica conecta el ente con el ser. Esta diferencia, nos dice Schürmann, puede ser usada para entender el enlace entre una ontología fenomenológica y una filosofía práctica, y hasta hacer derivar la filosofía política de la ontología (en Heidegger este intento, aunque escondido, no está ausente). El símbolo constituye para Schürmann un área de la realidad cuyo entendimiento no es meramente teórico, sino que requiere una cierta manera de vivir (segundo punto), pues para entender de verdad el sentido de un símbolo se necesita una determinada práctica de vida. De hecho nunca se entenderían los efectos de ninguna simbología hasta que no se la practicara en primera persona. Esto porque en todo símbolo lo que es simbolizado llama a la escucha del interprete y "pide" desvelar el origen del símbolo. Lo mismo pasa en la diferencia simbólica entre ser y entes, donde el ser "llama" al ser humano, en su existencia práctica y diaria, a entenderlo en cuanto ser. Según la terminología heideggeriana, este entendimiento del ser como liberación (Gelassenheit), pasa a través de una modalidad de la existencia, la del hombre libre. La liberación es entonces una actitud (fenomenológica podríamos decir) que deja que las cosas sean, y sólo de esta forma se puede aprehender el sentido del ser "en sí". Sólo así el ser se revela por lo que es, es decir, la nada que deja ser: si un fenómeno es dejado ser, entonces el ser aparece como lo que deja-ser ${ }^{53}$. Schürmann no podría ser más claro al decir que:

el ser se enseña como liberación (releasement) sólo a una existencia que es ella misma perfectamente libre, y pensar el ser como liberación libera la existencia. ${ }^{54}$

\footnotetext{
52 Ibidem, pp.196-197.

53 Ibidem, pp. 198.

54 Ibidem, pp. 201.
} 
Ahora bien: esta liberación tiene, según Schürmann, cinco claras consecuencias políticas. Primero, la liberación de la teleología en la acción: encontrar una finalidad en la existencia significa darle una razón, un sentido último, una metafísica; en cambio, el hombre verdaderamente libre es aquel que "vive sin un por qué". El concepto de teleología siempre ha servido para dirigir la conducta humana y hacer depender un comportamiento (aceptable) de una finalidad considerada buena o deseable. Pero si una conducta (inducida por los símbolos) no tiene finalidad alguna, entonces renunciamos a otorgarle un sentido. Estos son los momentos en los que nos adherimos a los símbolos y el ser mismo se manifiesta en cuanto símbolo y ya no como simbolizado 55 .

La segunda consecuencia entraña el principio de responsabilidad, que implica que la persona en cuestión esté llamada a responder por sus actos hacia los demás. Pero cuando el ser pierde sus caracteres sustantivos, cuando ya no hace de referente de las acciones humanas, entonces el hombre ya no se ve llamado a adecuar su acción a una supuesta "rectitud". En pocas palabras: el sujeto se libera finalmente del pesar de la coincidencia entre acción y explicación de la misma. Parafraseando a Meister Eckhart (su otra gran influencia aparte de Heidegger), según el cual la responsabilidad es la peor esclavitud, Schürmann dice "los que quieren algo por sus acciones, los que actúan según un por qué, son apostadores y mercenarios" 56 .

La tercera y más directa repercusión es la protesta. Una protesta que se arroja contra el mundo administrado por la tecnología que, en su todavía deseable empeño desfundador, se arriesga a ser un universo cerrado que acaba por proponer una nueva metafísica ${ }^{57}$. Después de la muerte de la teleología y el deslizamiento del principio de responsabilidad, el aparato tecnológico se vuelve un ambiente, que como tal excluye los otros ambientes. Es como si la tecnología, a pesar de que haya contribuido a derrumbar toda pretensión metafísica, se arrogara el derecho de establecer de una vez por todas el sentido del ser. De hecho, el hombre que vive en la edad de la técnica queda reducido a una función en el interior de la máquina tecnológica. El peligro, según Schürmann, es lo de volver a proponer la pregunta aristotélica acerca de cuál es la función del hombre, suponiendo una raíz y un destino innatos al ser humano, es decir una metafísica. Así pues, la protesta es la tentativa nunca adormecida de dejar abiertos más horizontes de sentidos, nuevas constelaciones de verdad 58 .

55 Ibidem, pp. 203.

56 Ibidem, pp. 205-206.

57 Con respecto a la cuestión de la técnica, véase: Heidegger, M.: "La pregunta por la técnica", en Heidegger M.: Conferencias y artículos (trad. Eustaquio Barjau), Barcelona, Ediciones del Serbal, 1994; Heidegger, M.: Gesamtausgabe 76: Leitgedanken zur Entstehung der Metaphysik, der neuzeitlichen Wissenschaft und der modernen Technik (ed. Claudius Strube), Frankfurt am Main, Vittorio Klostermann, 2009; y Heidegger, M.: Gesamtausgabe 79 Bremer und Freiburger Vorträge (de. Petra Jaeger), Frankfurt am Main, Vittorio Klostermann, 1994.

58 Ibidem, pp. 208-209. 
El cuarto reflejo de la muerte de la metafísica es un nuevo entendimiento acerca del destino humano. Aquí, la lectura de Schürmann está fuertemente influida por el anti-humanismo heideggeriano. Según él, no sólo el destino ya no es una decisión humana (esto tendría sentido sólo si se sigue aceptando las tradicionales categorías metafísicas de hombre e historia), sino que tampoco depende del ser. El ser "cede el paso" al Ahora, que libera al ser humano de cualquier finalismo histórico $\mathrm{y}$, en primer lugar, del tiempo entendido como temporalidad estática y como cultura histórica. El sujeto se encuentra finalmente desvinculado en su praxis, de toda acción finalística. Dicho de manera más sencilla: el sujeto ya no "tiene que" cumplir con una finalidad determinada, sino que se afirma en la libre elección del Ahora 59 .

Por último, la anarquía. Así lo explica Schürmann: "el origen, simbolizado en el ser, es siempre múltiple y finito, no es el principio de las cosas, el solo y simple arché. No es para nada un principio, más bien es anárquico"60. En conclusión: entender el ser como plural implica el paso de un pensamiento metafísico a uno posmetafísico. El entendimiento del origen como un evento preciso en el que las constelaciones de verdad se agregan y se desagregan, significa superar una lógica monista que confiere al ser una objetividad estática. Pero un ser que se desarrolla siempre en nuevas articulaciones, es decir, un ser inestable, amenaza políticamente la tradicional legitimad de toda autoridad. Si los símbolos se refieren a un origen que ya no satisface los requisitos de razón, es decir, si la diferencia simbólica es sustancialmente anárquica, entonces se pierde al mismo tiempo el fundamento especulativo que legitimaba toda clase de autoridad. A pesar de un contenido político visiblemente anarquista, Schürmann distingue claramente la anarquía del anarquismo, siendo la anarquía un anarquismo ontológico, un rechazo de los principios metafísicos como el de la esencia humana, y afirma en cambio una acción sin garantías universales o fundamentos estables. Por esto, es menester distinguirla del anarquismo de Kropotkin o Bakunin, siendo este último una mera inversión del sitio del poder:

Lo que estos maestros buscaban era desplazar el origen, sustituir el poder de la autoridad, princeps, por el poder racional, principium. Operación "metafísica" si la hay. Reemplazo de un punto de vista por otro. La anarquía de la que se trata es el nombre para una historia que acaece en el fundamento del obrar, historia en la que los cimientos ceden y en la que se percibe que el principio de cohesión, sea él autoritario o racional, no es más que un espacio en blanco, sin poder legislador sobre la vida. La anarquía nombra el destino que hace perecer los principios a los que, después de Platón, los occidentales han referido sus hechos y sus gestas para anclarlos allí, sustrayéndolos al cam-

59 Ibidem, p. 212.

60 Idem. 
bio y a la duda. Es la producción racional de este anclaje [...] la que se torna ya imposible con Heidegger.61

El equivalente político de una anarquía ontológica es necesariamente "la" anarquía. El error del hombre y del filósofo Heidegger, según Schürmann, habría sido el de haber confundido un régimen totalitario con sus esperanzas anarquistas y antiautoritarias ${ }^{62}$. Pues la abolición práctica de un arché y de un télos en la acción, la transvaloración de la responsabilidad y del destino, y la protesta contra un mundo reducido cada vez más a un puro funcionamiento, serían los ingredientes políticos del segundo Heidegger. Es ahora evidente lo que decíamos al principio del apartado: una lectura convencional de Heidegger, que vaya desde la analítica existencial hasta la topología del ser, opta por la unidad a costa de la multiplicidad (que es al fin y al cabo el Führerprinzip); pero si leemos Heidegger al revés, desde la topología hasta la analítica, el cuadro cambia. En lugar de un terreno unitario está la liberación, en lugar del sometimiento del saber universitario a los imperativos del sistema, está la protesta contra de la tecnología y la cibernética, en lugar de la identificación entre el Führer y la ley, la anarquía63. Así pues, privilegiar una lectura schürmanniana de Heidegger alumbra aspectos de su pensamiento dados muchas veces ya por asumidos, como la discutida cuestión de la autenticidad. Si en Heidegger el ser auténtico es el ser para la muerte, es decir el ser que cobra plenamente conciencia de sus posibilidades, entonces lo que le pertenece como rasgo más propio son justo estas potencialidades, es decir, la libertad de existir "sin un por qué". Schürmann nos recuerda que posibilidad en alemán se dice Möglichkeit, que deriva de mögen, de vermögen, ser capaz de, y comparte la misma raíz de Macht, poder. El poder contiene entonces la misma esencia anárquica de la potencialidad, que pero tiene que ser pensado como el fruto de un acuerdo entre los actores y no como el resultado de un acto de fuerza (Gewalt). Concluyendo, Schürmann se mueve en un ámbito político entre colectivismo e individualismo. No se trata, como precisa, de una teoría de la organización de los hombres en colectividades, y tampoco de la pura celebración de la interioridad, sino de una vía media entre un sistema de constitución social y su negación por obra de un individualismo espiritual. Así pues, hay que rechazar tanto las exigencias pragmáticas de la administración pública, como su escape romántico ${ }^{64}$.

De lo dicho hasta ahora, resulta evidente que la particular anarquía ontológica de la cual nos habla Schürmann no se traduce en un programa político concreto. La lectura deconstructiva de la historia metafísica busca más bien "liberar" la práctica

\footnotetext{
61 Schürmann R.: Heidegger... op.cit.: p. 6.

62 Schürmann R.: Political Thinking... op.cit, p. 215.

63 Ibidem, p. 216.

64 Ibidem, p. 210.
} 
de la teoría, la acción del pensamiento. Como ya se ha dicho, la vieja unidad entre pensamiento y acción se desvanece una vez que actuar ya no significa ajustar la conducta diaria, tanto pública como privada, al fundamento racional del cual deriva el sistema de saber y poder. Pero si ya no es posible derivar una práctica política (y una ética) de la filosofía primera (tal y como querían los antiguos), entonces la pregunta fundadora de la política (moderna), esto es, “¿qué hacer?” debe ser totalmente replanteada. Es decir, si los principios últimos ya no fundan y por lo tanto de ellos no se puede derivar ninguna conducta práctica, la práctica misma se libera de toda coacción que la vincule (llámese sustancia, Dios, cogito, bien común etc.). En pocas palabras, una vez que el modelo o el canon de la acción pierda su carácter de principio para el actuar, el actuar mismo no tiene ningún otro "fundamento" que la anarquía. Resulta claro por tanto por qué Schürmann renuncia a proponer algún tipo de organización política concreta. Hacer esto significaría subordinar una vez más una práctica, "anárquica" según vimos, a algún principio último. También vimos cómo la liberación del arché es también la liberación del télos. A nivel de práctica política, esto significa desvincular la acción de la consecución de una finalidad. En pocas palabras, Schürmann no está interesado, como los "maestros" Bakunin o Proudhon, en fundamentar una nueva praxis política, sino más bien en liberar la praxis de la dictadura del arché y del télos:

el aviso heideggeriano de dejar el campo libre a las cosas contiene también un imperativo. Las "cosas" en su venida al "mundo" se distinguen de los productos en que estos últimos sirven para un empleo. El fin útil constituye el ser mismo del Zeug, de los útiles. [... .] Desde el punto de vista de las economías, finalmente, "dejar el campo libre a las cosas" equivale a comprometerse en un pasaje, aquel que lleva de la violencia a la anarquía. Pasaje de un lugar donde los entes están coaccionados bajo un principio epocal a un lugar donde su contingencia radical es restaurada. Pasaje de las "sustancias" determinadas por un arché y un telos ideales, a las "cosas" que emergen con precariedad en su mundo él mismo precario. 65

Schürmann ve con claridad que si la pregunta política sigue a la ontológica, y si del ser "ya no queda nada", entonces la acción política no puede ser sino anárquica en el sentido más radical: sin fundamento y sin fin:

A la pregunta ¿Qué hacer?, cuando es puesta junto a la pregunta ¿Qué es el ser?, el fenomenólogo radical sólo puede responder: desalojar de su retiro a esos vestigios de una economía teleocrática [... .] y liberar así a las cosas del "concepto ordinario" que los "captura" bajo representaciones últimas. 66

65 Ibidem, pp. 279-280.

66 Ibid. 
Si quisiéramos simplificar, podríamos decir que Schürmann va de la liberación ontológica a la liberación política (o mejor ético-política). Igual que Vattimo, Schürmann es consciente de que los hombres y las mujeres se han infligido sufrimientos enormes en nombre de los principios epocales. Estando así las cosas, el pensar no es una empresa inútil en la medida en que finalmente libera a estos hombres y mujeres de la tiranía de principios últimos que oprimen su conducta y la de los demás. Por eso, si Schürmann insiste una y otra vez en diferenciar la economía anárquica tanto de la anarquía del poder como del anarquismo, es porque su anarquía, antes de ser una práctica política, es sobre todo un "imperativo ontológico". Pero tampoco se podría confinar la anarquía al ámbito exclusivamente ontológico y existencial (el "vivir un por qué"). El mismo autor precisa que esta manera de entender la anarquía abre a "un modo alternativo de pensar la vida en sociedad"67. Aunque Schürmann, coherentemente con sus ideas, renuncie a indicar un nómos social que permita gestionar la vida colectiva, no duda en vislumbrar una serie de prácticas múltiples y mutables:

la base para una alternativa a una filosofía política de la organización tendrá que ser tan multifacética como para permitir una respuesta siempre nueva gracias a la cual el ser desestabiliza patrones familiares de pensar y actuar. 68

El proyecto filosófico-político de Schürmann, aunque no abarque los temas de la filosofía política clásica o moderna, ni conteste a sus preguntas, puede ser interpretado como una apuesta por la autonomía. Autonomía respecto de los principios últimos y fundadores de los que seguían dependiendo los anarquistas del siglo decimonoveno (la Moral, la Esencia humana, etc.). En este sentido, la anarquía de Schürmann es políticamente más radical que el anarquismo como proyecto político revolucionario. De hecho la democracia, para ser de verdad radical, sólo puede brotar de un trasfondo anárquico, independiente de cualquier principio o autoridad. En un momento dado, Schürmann llega incluso a invocar la democracia directa, contra las metafísicas que sostienen "los contratos con el gobierno, y el mecanismo de la democracia representativa"69. La deconstrucción de los fundamentos se traduce en el rechazo político de todo ideal o norma heterónoma. La autonomía sería entonces el acto político de liberación del origen que ya no determina la vida colectiva y pública. Tal vez la debilidad del pensamiento de Schürmann sea la de no haber sabido (o querido) profundizar este punto.

\footnotetext{
67 Schürmann, R.: Political thinking... op.cit.: p. 220.

68 Schürmann, R.: The ontological... op.cit.: p. 115.

${ }^{69}$ Schürmann, R.: "Legislation-Transgression: Strategies and Counter-strategies in the Transcendental Justification of Norms", Man and World, vol. 17, 1984, 361-398, p. 392.
} 


\section{Conclusión}

¿Qué hacer entonces ante el fin de la metafísica? Si el "mundo verdadero", de reminiscencia nietzscheana, se ha vuelto fábula, no por eso la fábula ha perdido su encanto. La invitación de Schürmann a "dejar el campo libre a las cosas", liberar el pensamiento de toda representación finalística, es sin duda una invitación grávida de una carga política. Contestando a la cuestión política “¿qué hacer?”, el filósofo holandés nos alienta a despojar las cosas de sus ataduras a los principios epocales, reivindicando su destrucción. Al contrario que Vattimo 70 , Schürmann hace un llamamiento a un papel activo de la filosofía, cómplice por demasiado tiempo de un pensamiento autoritario y discriminatorio, y cuya tarea debería ser ahora precisamente la de deconstruir las épocas revelando lo infundado de sus principios. Sólo así puede "cambiar el mundo" y pensarlo más allá de cómo se manifiesta a primera vista (cuando se dice comúnmente "así es el mundo"), pues se llega a la conclusión de que sus principios, sus reglas, su moral no son nada más que figuras históricas infundadas. Pero el gran mérito de Schürmann es sobre todo el de haber recuperado la dimensión existencial de la anarquía. Según él, antes de una rebelión contra toda metafísica, hace falta cobrar conciencia y aceptar la falta de fundamentos en nuestra propia vida, una "vida sin por qué". ${ }^{71} \mathrm{Y}$ sin embargo su propuesta de estudiar fenomenológicamente los principios epocales (Dios, las Ideas, la Ley, la Razón, el Progreso, etc.) para luego destruirlos convirtiéndolos en nada, por convincente que parezca, es incompleta. En su tentativa de mostrar el principio fundamentalmente anárquico del arché, la nada que se encuentra en la base de las economías epocales, Schürmann olvida la enseñanza de Vattimo y la idea de la imposibilidad de una superación total de la metafísica y de su carácter todavía coactivo. Aunque la crisis del fundamento ponga en entredicho la propia condición de previsibilidad del actuar, que hasta ahora ha sido garantizada por formas de absolutización del momento simbólico normativo, no implica de ninguna manera que haya un debilitamiento efectivo del principio. En este sentido, la inconclusa polémica con Vattimo ha de ser reconsiderada. La diferencia entre los dos pensadores, como vimos, no reside tanto en sus concepciones divergentes del ser, en cuanto para ambos el ocaso del ser implica el descenso de las ideas fuertes e impositivas, sino más bien en el cómo acontece esta sustracción. Mientras para Schürmann el ser se

\footnotetext{
70 Según Vattimo, la filosofía no puede ni debe enseñar a dónde nos dirigimos, sino sólo vivir en la condición de quien no se dirige a ninguna parte; de ahí también una especial concepción del "pensador débil" como aquel a quien "la falta de un auténtico proyecto propio, el puro recorrer, como un parásito, aquello que ya ha sido pensado; y hacerlo, además, animado por un propósito sustancialmente edificante y estético: el de revivir el pasado como tal, con el único fin de gozar de él en una especie de "degustación arqueológica" propia de un anticuario." (cfr. Vattimo, G.: El pensamiento débil (trad. Luis de Santiago), Madrid, Cátedra, 1988, p. 35).

71 Schürmann, R.: Heidegger... op.cit.: p. 244.
} 
da en presencia como ausencia de fundamento, como anarquía, en cambio para Vattimo el advenimiento del ser siempre se da en la ausencia, como algo pasado que podemos recordar cuando ya se nos haya substraído. En la opinión de quien escribe, podríamos mantener las dos posturas, sin necesidad de choque o conflicto alguno. Se trata de acercar el plano teórico y el práctico. Es decir, una concepción teórica no metafísica de la verdad no ha de cegarnos acerca de las consecuencias prácticas/existenciales de la (im)posibilidad de su superación. Ignorar dicha distinción significaría caer victimas del pensamiento metafísico y de la ingenua convicción de que su superación es puramente un acto de voluntad. En este sentido, Vattimo da en el blanco cuando subraya que, para desprenderse de la metafísica, es necesario rememorarla: sólo recorriendo la historia de la metafísica como olvido del ser, al Dasein le es posible concebirse como totalidad hermenéutica cuyo fundamento es exactamente la ausencia de fundamento ${ }^{72}$. El ser es entonces ya sido, de ello "ya no queda nada más" (por repetir el refrán heideggeriano), y sólo recordándolo es posible entender su nada constitutiva. El pensamiento rememorante, por tanto, no es una forma de añoranza del pasado ni un remitirse agradecido a alguna presencia de la cual dependeríamos, sino captar la apertura del ser a la cual estaríamos arrojados. Ésta es su función liberadora porque nos liberaría de las evidencias de un ser pensado fuerte ${ }^{73}$.

En conclusión, podríamos lanzar la apuesta de actuar como si no existiera fundamento alguno y pensar como si fuera imposible desprenderse totalmente del fundamento. En otras palabras, hay que tener presente cómo opera a nivel tanto individual como social (imposible considerar el uno sin el otro) la experiencia crepuscular de la metafísica, es decir, cuáles son las modalidades experienciales a través de las cuales se da el ocaso del ser. Sin duda, esto ha sido el objetivo latente de toda nuestra investigación sobre Schürmann: procurar entender cómo actúa la categoría de lo universal en la experiencia cotidiana del hombre de carne y hueso. No dudamos de hecho en afirmar que los conceptos de "ocaso del ser", "pensamiento débil", "anarquía" no son nada más que conceptos, actitudes cognoscitivas, hermosas ideas académicas que sin embargo siguen sin afectar la práctica diaria en cuanto la mayoría seguimos pensando, como constató Pier Aldo Rovatti (autor junto a Vattimo del pensamiento débil), que la realidad tiene un trasfondo homogéneo, que el ser se esconde pero que está allí, así como seguimos confiando en la identidad trascendental del sujeto ${ }^{74}$. No se trata de que la misma estructura metafísica permanezca intocable, ya que van progresivamente debilitándose los contenidos fuertes que la sustentan (piénsese en el ocaso de las religiones tradicionales), sino que el hombre va

\footnotetext{
72 Vattimo, G.: El fin de la modernidad (trad. Alberto L. Bixio), Barcelona, Gedisa, 1987, pp. 106-107.

73 Vattimo, G.: Las aventuras de la diferencia (trad. Juan Carlos Gentile), Barcelona, Ediciones Península, 1986, p. 119.

74 Rovatti, P.A... : en G. Vattimo: El pensamiento... op.cit.: pp.42-43.
} 
progresivamente adaptándose al obscurecimiento (casi siempre lento) de una epoché y su pasaje a otra (este pasaje, nos lo dice el propio Heidegger, no se desarrolla en un recorrido historicista que deduzca una época de la otra, so pena de caer en alguna forma de hegelianismo ${ }^{75}$ ).

Sin embargo, la tesis de Vattimo, a pesar de los esfuerzos hermenéuticos, no permite una verdadera salida del paradigma, que el autor italiano no vislumbra ni en la experiencia existencial del sin-fundamento, ni en una posibilidad de abandono tout court de la metafísica. Por su parte Schürmann avanza una hipótesis intrigante: el ser, que se da en horizontes histórico-lingüísticos, se manifiesta de forma aún más evidente en la transición entre una época y otra, cuando viene a la luz el carácter no definitorio de los fundamentos. Cuando, en otras palabras, las "hegemonías" que garantizaban el mantenimiento de una época son finalmente brisées, $\operatorname{rotas}^{76}$. Hay entonces un "espacio vacío" entre las épocas, un vacío de poder, por así decirlo, que pone de manifiesto la falta de fundamento del arché. Esto es lo que nos permite ver el cielo vaciado de los dioses. Allí es donde hemos de "insinuarnos", manteniendo el radical vacío y haciendo que el lugar no se vuelva ocupable. En substancia la anarquía, que reposa como principio escondido de cada época, se manifiesta en la transición entre épocas, es decir en el momento de crisis, y es posible captarla sólo manteniendo diariamente la "mente abierta", es decir, aceptando individualmente aquella situación de indeterminación y aleatoriedad que Schürmann nos ha indicado como "a priori práctico".*

\section{Referencias bibliográficas}

CARChIA, G.: "Introduzione", en R. Schürmann, Dai principi all'Anarchia. Essere e agire in Heidegger Milano, Il Mulino, 1995.

HeIDEgGer, M.: Aportes a la filosofia: acerca del Evento (trad. Dina V. Picotti C.), Buenos Aires, Biblos, 2006.

HeidegGer, M.: "La pregunta por la técnica", en M. Heidegger, Conferencias y artículos (trad. Eustaquio Barjau), Barcelona, Ediciones del Serbal, 1994

Heidegger, M.: Ser y tiempo (trad. Jorge Eduardo Rivera), Santiago de Chile, Editorial Universitaria, 1997.

Heidegger, M.: Caminos de Bosque (trad. Arturo Leyte y Helena Cortés), Madrid, Alianza, 2010.

75 Heidegger, M.: La proposición del fundamento (trad. Félix Duque y Jorge Pérez de Tudela), Barcelona, Ediciones del Serbal, 1991.

76 Cfr. Schürmann, R.: Broken... op.cit.

* Quiero agradecer a los dos revisores anónimos por los útiles consejos que han permitido publicar este trabajo. Un agradecimiento especial va dirigido a Jesús García Rodríguez por la cuidadosa revisión gramatical y lexical. 
HEIDEGGER, M.: Escritos sobre la universidad alemana (trad. Ramón Rodríguez García), Madrid, Tecnos, 1996.

HeidegGer, M.: Gesamtausgabe 67: Metaphysik und Nihilismus, Frankfurt am Main, Vittorio Klostermann, 1999.

HeIDEGGER, M.: Gesamtausgabe 76: Leitgedanken zur Entstehung der Metaphysik, der neuzeitlichen Wissenschaft und der modernen Technik (ed. Claudius Strube), Frankfurt am Main, Vittorio Klostermann, 2009.

HeidegGer, M.: Gesamtausgabe 79: Bremer und Freiburger Vorträge (de. Petra Jaeger), Frankfurt am Main, Vittorio Klostermann, 1994.

HeIDEGger, M.: La proposición del fundamento (trad. Félix Duque y Jorge Pérez de Tudela), Barcelona, Ediciones del Serbal, 1991.

HeidegGer, M.: Seminario en Le Thor, (trad. Diego Tatian), Córdoba, Alción Editora, 1995.

Leyte, A.: Heidegger, Madrid, Alianza Editorial, 2006.

Lilly, R.: "The Topology of Des Hégemonies Brisées", Research in Phenomenology, n. 28, 1998, pp. 226-242.

Martinengo, A.: Introduzione a Reiner Schürmann, Roma, Maltemi, 2008.

Ortiz-Oses, A.: Heidegger y el ser sentido, Bilbao, Universidad de Deusto, 2009.

PögGeller, O.: El camino del pensar de Martin Heidegger (trad. Félix Duque), Madrid, Alianza Editorial, 1993.

SCHÜRMANN, R.: "Deconstruction is not enough: on Gianni Vattimo's call for "Weak Thinking"”, Graduate Faculty Philosophy Journal, volume 10 n. 1, Spring 1984.

SchÜrmann, R.: Heidegger on Being and Acting. From Principles to Anarchy, Bloomington, Indiana University Press, 1986.

SCHÜRMANN, R.: Le principe d'anarchie : Heidegger et la question de l'agir, Paris, Seuil, 1982.

SchÜRmann, R.:. "Legislation-Transgression: Strategies and Counter-strategies in the Transcendental Justification of Norms," Man and World, vol. 17, 1984, 361-398.

SchÜRmann, R.: "Political Thinking in Heidegger", Social Research, vol. 45, n. 1, Spring 1978, pp.191-221.

SCHÜRmAnN, R.: "Technicity, topology, tragedy: Heidegger on "That Which Saves" in the global reach", en A.M. Meltzer, J. Weinberger \& M.R. Zinman, Technology in the Western Political Tradition, Ithaca, N.Y.: Cornell University Press, 1993.

SCHÜRmann, R.: The ontological difference in practical philosophy, "Philosophy and Phenomenological Research", vol 40 n. 1, sept 1979, pp. 99-122.

SchÜRmann, R.: Tres "pensadores del abandono": Meister Eckhart. Heidegger, Susuki, Paideia, Córdoba, 1995. 
Vattimo, G.: El pensamiento débil (trad. Luis de Santiago), Madrid, Cátedra, 1988. VAтtimo, G.: El fin de la modernidad (trad. Alberto L. Bixio), Barcelona, Gedisa, 1987.

VATtimo, G.: Ética de la interpretación (trad. Teresa Oñate y Zubia), Barcelona, Paidós, 1991.

Vattimo, G.: Introducción a Heidegger (trad. Alfredo Báez), Barcelona, Gedisa, 1992.

Vattimo, G.: Las aventuras de la diferencia (trad. Juan Carlos Gentile), Barcelona, Ediciones Península, 1986.

Vattimo, G.: Más allá del sujeto (trad. de Juan Carlos Gentile Vitale), Barcelona, Paidós, 1992.

Vitiello, V.: Historia, naturaleza y redención, en F. Duque, Los confines de la modernidad. Diez años después de Heidegger, Barcelona, Granica, 1988.

Volpi, F.: El nihilismo (trad. Cristina I. del Rosso y Alejandro Vigo), Buenos Aires, Editorial Biblos, 2005.

Valerio D'Angelo

Universidad Autónoma de Madrid

valeriodangelo@ymail.com 